\title{
Retrospective Analysis of the Performance of a New-Generation Dual Pump Phaco System Using Two Sizes of Phaco Tips in Cases with Different Nuclear Hardness
}

\author{
Norbert Körber \\ Augencentrum Köln, Cologne, Germany \\ Email: n.koerber@gmx.de
}

Received 4 May 2016; accepted 8 July 2016; published 11 July 2016

Copyright (C) 2016 by author and Scientific Research Publishing Inc. This work is licensed under the Creative Commons Attribution International License (CC BY). http://creativecommons.org/licenses/by/4.0/

(c) (i) Open Access

\begin{abstract}
Purpose: To evaluate the performance of a phacoemulsification system in terms of effective (EPT) and total phaco time (TPT) using 20G and 21G phaco tips. Methods: Retrospective comparative study including 143 consecutive cataractous eyes undergoing phacoemulsification cataract surgery with the Visalis 500 device. The $20 \mathrm{G}$ and $21 \mathrm{G}$ phaco tips were used in 46 and 97 eyes, respectively. The EPT and TPT values were evaluated. Results: Median TPT was $11.25 \mathrm{~s}$ and $17.50 \mathrm{~s}$ in the $20 \mathrm{G}$ and 21G groups, respectively $(p=0.0011)$. Median EPT values were $3.15 \mathrm{~s}$ and $5.00 \mathrm{~s}$ in the 20G and 21G groups, respectively $(p=0.0032)$. TPT and EPT were significantly lower in $3 / 3+$ cataract eyes compared to $4 / 4+$ using both tips $(p<0.001)$. Conclusions: The Visalis 500 allows cataract surgery with reduced TPT and EPT, even in hard cataracts. The use of the 20G phaco tip provides an additional benefit in terms of reduction of phaco time.
\end{abstract}

\section{Keywords}

Effective Phaco Time, Total Phaco Time, Tip Size, Nuclear Density, EPT

\section{Introduction}

The latest phacoemulsification platforms allow an optimized control of fluidics and surgical time in cataract surgery [1] [2]. This leads to safer and more efficient surgical procedures with significant reduction of the induced phacoenergy and duration, and, consequently, with minimal or no impact on corneal and anterior chamber structures [1] [2]. Lowering the amount of energy entering the anterior chamber during cataract surgery de- 
creases the risk for endothelial cell loss [3]-[5] and for damaging the blood/aqueous barrier and therefore has the potential to reduce the level of postoperative inflammation [6].

The highest level of phacodynamics control is currently reached with the hybrids or dual pump phacoemulsification systems that combine peristaltic and Venturi pumps, making use of the advantages of both pump options [7] [8]. Venturi-based vacuum provides increased efficiency and decreased chatter at lower vacuum levels [9]. Recently, a new dual pump phaco-system was commercially released, the Visalis 500 (Carl Zeiss Meditec, Jena, Germany) that combines the benefits of peristaltic and Venturi pumps and allows surgeons to make aspiration and cutting rate adjustments independently of each other. The objective of the current study was to analyze the performance of this new system in terms of effective (EPT) and total phaco time (TPT) in cataract eyes with different levels of nuclear hardness using the $20 \mathrm{G}$ and $21 \mathrm{G}$ phaco tips.

\section{Material and Methods}

\subsection{Patients}

In this retrospective comparative study, 143 (47 males and 96 females) consecutive cataractous eyes undergoing cataract surgery during a 3 month period were included. Mean patient age was $72 \pm 5$ years. The 20G phaco tip was used in 46 eyes (20G group), whereas the $21 \mathrm{G}$ phaco tip was used in 97 eyes (21G group). The inclusion criteria of this study were a patient age of 45 or older and presence of a senile cataract of N3-4 according to the Lens Opacification Classification System III (LOCSIII) [10] and a visual acuity of 0.4 (decimal) or less. The exclusion criteria were glaucoma, corneal opacities, cornea guttata, abnormal iris, macular degeneration or retinopathy, previous posterior segment surgery, neurophthalmic disease, or history of ocular inflammation. All subjects were adequately informed and signed a consent form. The study adhered to the tenets of the Declaration of Helsinki.

\subsection{Surgery}

All surgeries were performed between February and April 2015 by the same surgeon (NK) using a standard sutureless coaxial phacoemulsification technique. The surgeon has more than 30 years of experience in the field of cataract surgery and scientific interest in cataract surgery technique and technical developments. Depending on the phaco tip diameter, a corneal limbalincision of 2.4 or $2.65 / 2.8 \mathrm{~mm}$ was initially performed, followed by two paracenteses of $1.2 \mathrm{~mm}$. After injection of a cohesive OVD (Hyalon Z plus, Carl Zeiss Meditec) in the anterior chamber, a curvilinear rhexis of 5 - $5.5 \mathrm{~mm}$ was performed. The phacodevice Visalis 500 (Carl Zeiss Meditec, Jena, Germany) was used in all cases for the phacoemulsification procedure during which the EPT and TPT were recorded. The Automated Programmable Modulation (APM) mode of the Visalis system was used. It combines the burst and the pulse patterns in each modulation cycle, which supports the chop technique very well by impaling the nucleus with the power of the burst and removing the quadrants with the speed of the pulse. The following phaco settings were used for 20G: bottle height $75 \mathrm{~cm}$, aspiration $350 \mathrm{mmHg}$. For 21G, the bottle height was $65 \mathrm{~cm}$ and the aspiration $400 \mathrm{mmHg}$. Implantation of the intraocular lens was performed after hydrodissection and aspiration through $2.4 \mathrm{~mm}$ using the $21 \mathrm{G}$ phacotip and through 2.65 to $2.8 \mathrm{~mm}$ using the $20 \mathrm{G}$ phaco tip. Wound sealing was confirmed at the end of the surgery by the negative Seidel test [11].

\subsection{Statistical Analysis}

SPSS statistics software package version 19.0 for Windows (IBM, Armonk, NY, USA) was used for statistical analysis. Normality of all data samples was first evaluated by means of the Kolmogorov-Smirnov test. When parametric analysis was possible, the Student $t$ test for unpaired data was used for the comparison between 20G and $21 \mathrm{G}$ groups as well as between nucleus hardness groups. Otherwise, when parametric analysis was not possible, the Mann-Whitney Test or the Kruskall-Wallis test was applied to assess the significance of differences between groups, using in all cases the same level of significance $(\mathrm{p}<0.05)$.

\section{Results}

The median of TPT over all lens hardnesses was $11.25 \mathrm{~s}$ (range, 5.2 to $39.1 \mathrm{~s}$ ) and $17.50 \mathrm{~s}$ (range, 4.80 to $56.50 \mathrm{~s}$ ) in the 20G and 21G groups, respectively (Figure 1). This difference among groups in TPT was statistically sig- 
nificant (Mann-Whitney test, $\mathrm{p}=0.0011$ ) (Figure 1).

Concerning the EPT, its median value over all lens hardnesses was $3.15 \mathrm{~s}$ (range, 0.9 to $15.1 \mathrm{~s}$ ) and $5.00 \mathrm{~s}$ (range, 1.00 to $20.90 \mathrm{~s}$ ) in the 20G and 21G groups, respectively (Figure 2). This difference in EPT among groups was also statistically significant (Mann-Whitney test, $\mathrm{p}=0.0032$ ).

In the 20G group, a total of 23 and 20 eyes with cataract of nuclear hardness $3 / 3+$ and $4 / 4+$ were operated, respectively. TPT was significantly lower in 3/3+ cataract eyes (median: $9.5 \mathrm{~s}$; range: 5.20 to $39.10 \mathrm{~s}$ ) compared to 4/4+ (mean: $20.52 \mathrm{~s}$; standard deviation: 6.79 s) (Mann-Whitney test, $\mathrm{p}<0.001$ ) (Figure 3).

Similarly, the EPT was also significantly lower in eyes with cataract 3/3+ (median: $2.5 \mathrm{~s}$; range: 1.20 to 11.10 s) compared to those with cataract 4/4+ (mean: $6.70 \mathrm{~s}$, standard deviation: $3.23 \mathrm{~s}$ ) (Mann-Whitney test, p < 0.001) (Figure 4).

In the $21 \mathrm{G}$ group, a total of 12,48 and 37 eyes with cataract of nuclear hardness $2 / 2+, 3 / 3+$ and $4 / 4+$ were operated, respectively. Significant differences in TPT were found among the subgroups of eyes with different levels of lens nuclear hardness (2/2+: mean $11.53 \mathrm{~s}$, standard deviation: $4.72 \mathrm{~s}$; 3/3+: median $14.80 \mathrm{~s}$, range: 4.80 to 37.80 s; 4/4+: mean 29.87 s, standard deviation: 10.07 s; Kruskal-Wallis test, p < 0.0001) (Figure 5).

Specifically, significant differences were found in TPT for eyes with lens nuclear hardness $3 / 3+$ and $4 / 4+$ (Dunn test, $\mathrm{p}<0.001$ ). There were also statistically significant differences in EPT between the subgroups of eyes with different levels of lens nuclear hardness (2/2+: mean $2.93 \mathrm{~s}$, standard deviation: $1.48 \mathrm{~s} ; 3 / 3+$ : median $4.20 \mathrm{~s}$, range: 1.00 to $13.30 \mathrm{~s}$; 4/4+: median $8.70 \mathrm{~s}$, range: 2.40 to $20.90 \mathrm{~s}$; Kruskal-Wallis test, $\mathrm{p}<0.0001$ ) (Figure 6). As with TPT, significant differences in EPT were found specifically between eyes with cataract 3/3+ and $4 / 4+$ (Dunn test, $\mathrm{p}<0.001$ ).

\section{Discussion}

In this study, the phacoemulsification device Visalis 500 has been used with its new ultrasound mode APM. This mode provides the efficiency of the burst to impale the nucleus and the speed of pulse to remove quadrants and should thus reduce the EPT. To this date, to our best knowledge, there is no study confirming this EPT

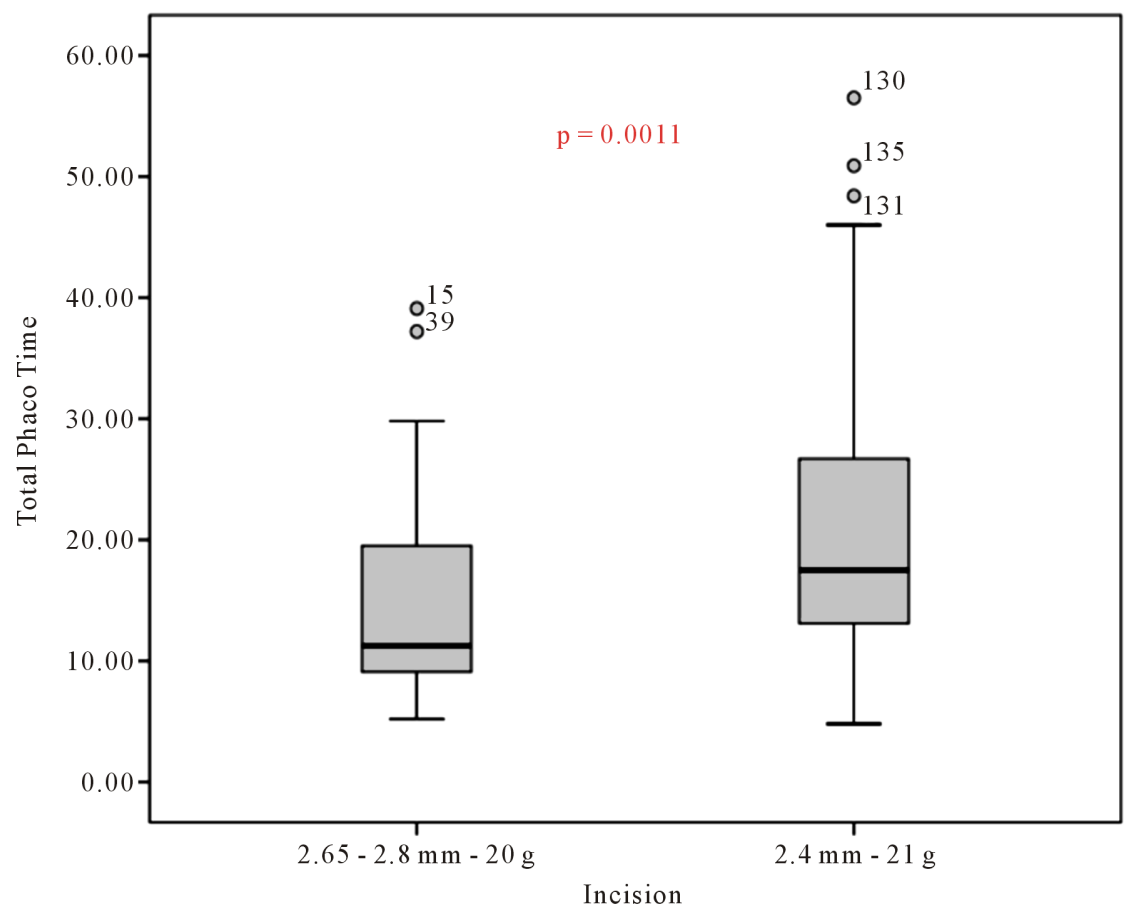

Figure 1. Box plot representing the distribution of the total phaco time (TPT) outcomes using the 20G and 21G phaco tips. The boxes represent the interquartile range (difference between the upper $75 \%$ and lower quartile $25 \%$ ); the thick black lines, the median; the whiskers, the highest and lowest values that were not outliers or extreme values; circles, outliers (values that are between 1.5 and 3 times the interquartile range); asterisks, extreme values (values that are more than 3 times the interquartile range). 


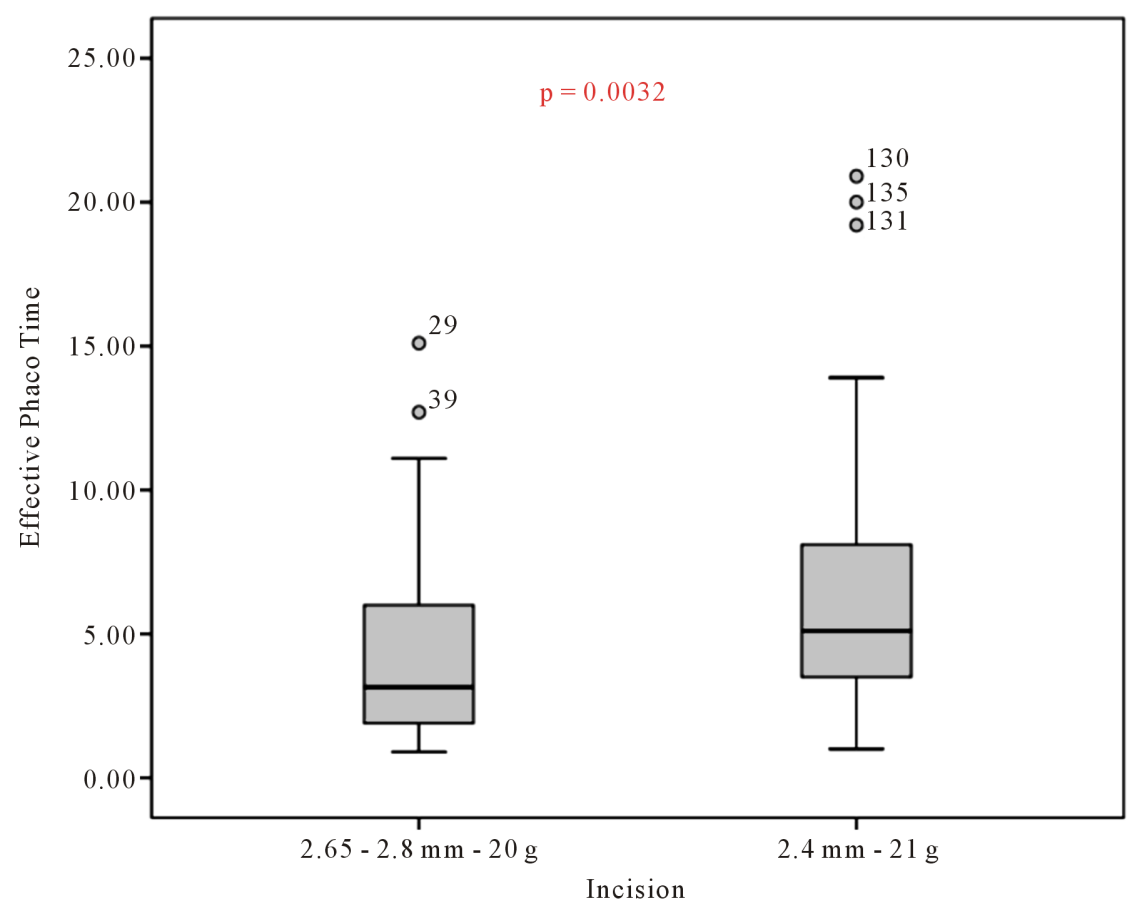

Figure 2. Box plot representing the distribution of the effective phaco time (EPT) outcomes using the 20G and 21G phaco tips. The boxes represent the interquartile range (difference between the upper $75 \%$ and lower quartile $25 \%$ ); the thick black lines, the median; the whiskers, the highest and lowest values that were not outliers or extreme values; circles, outliers (values that are between 1.5 and 3 times the interquartile range); asterisks, extreme values (values that are more than 3 times the interquartile range).

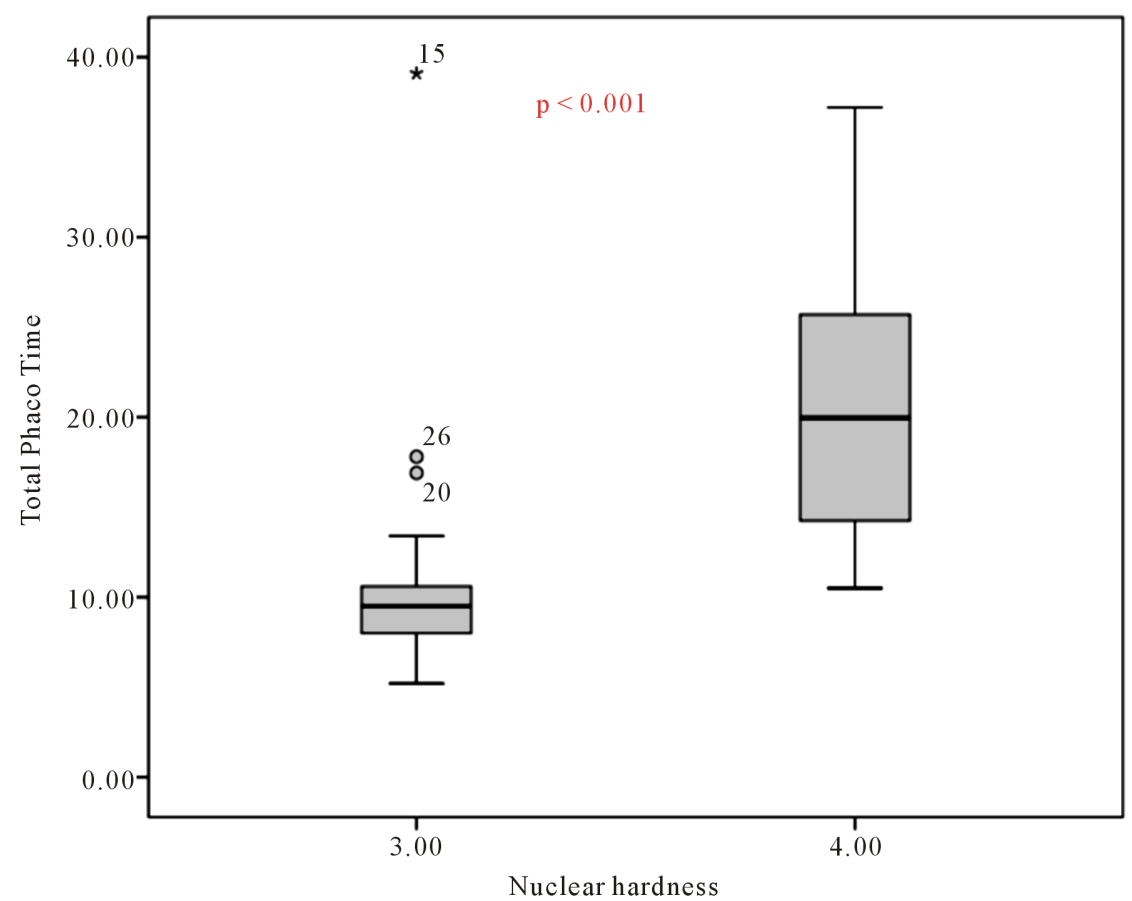

Figure 3. Box plot representing the distribution of the total phaco time (TPT) outcomes using the 20G phaco tip in eyes with cataract of nuclear hardness $3 / 3+$ and $4 / 4+$. The boxes represent the interquartile range (difference between the upper $75 \%$ and lower quartile 25\%); the thick black lines, the median; the whiskers, the highest and lowest values that were not outliers or extreme values; circles, outliers (values that are between 1.5 and 3 times the interquartile range); asterisks, extreme values (values that are more than 3 times the interquartile range). 


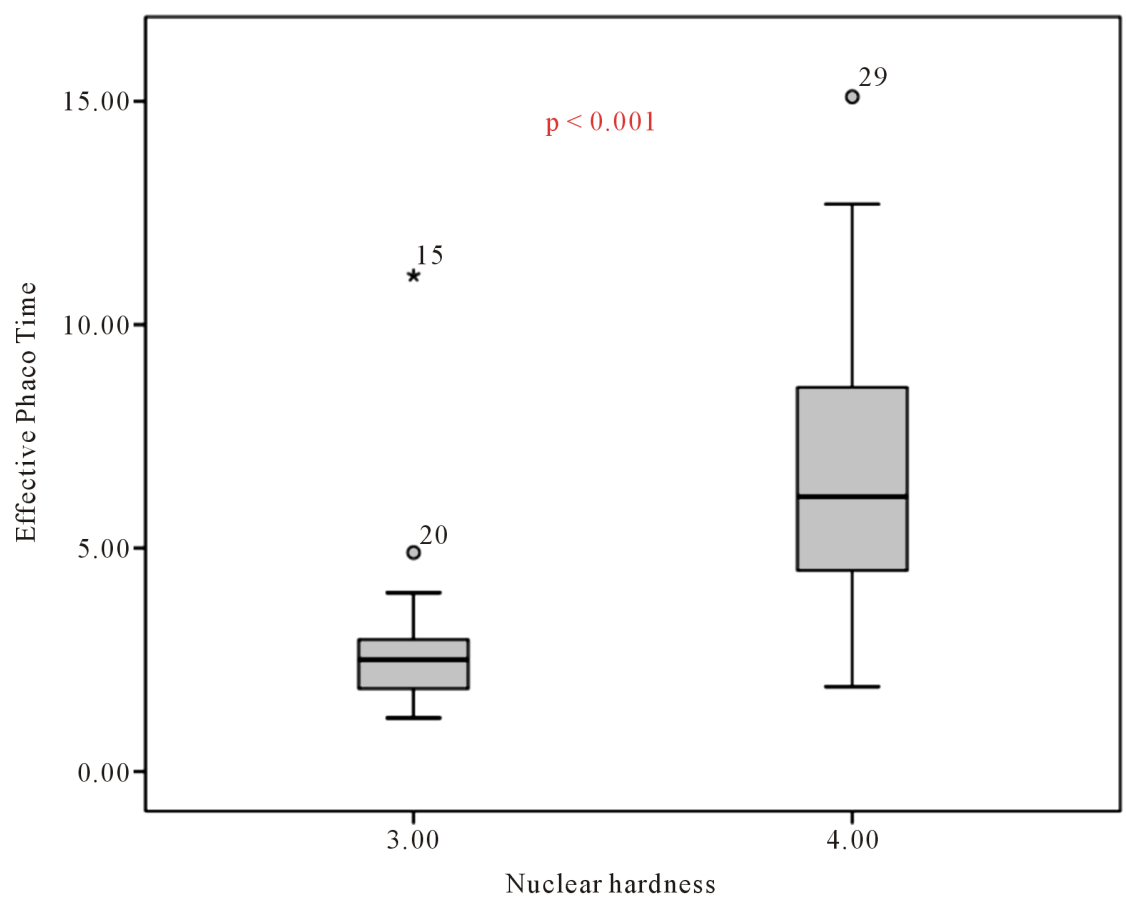

Figure 4. Box plot representing the distribution of the effective phaco time (EPT) outcomes using the 20G phaco tip in eyes with cataract of nuclear hardness $3 / 3+$ and $4 / 4+$. The boxes represent the interquartile range (difference between the upper $75 \%$ and lower quartile 25\%); the thick black lines, the median; the whiskers, the highest and lowest values that were not outliers or extreme values; circles, outliers (values that are between 1.5 and 3 times the interquartile range); asterisks, extreme values (values that are more than 3 times the interquartile range).

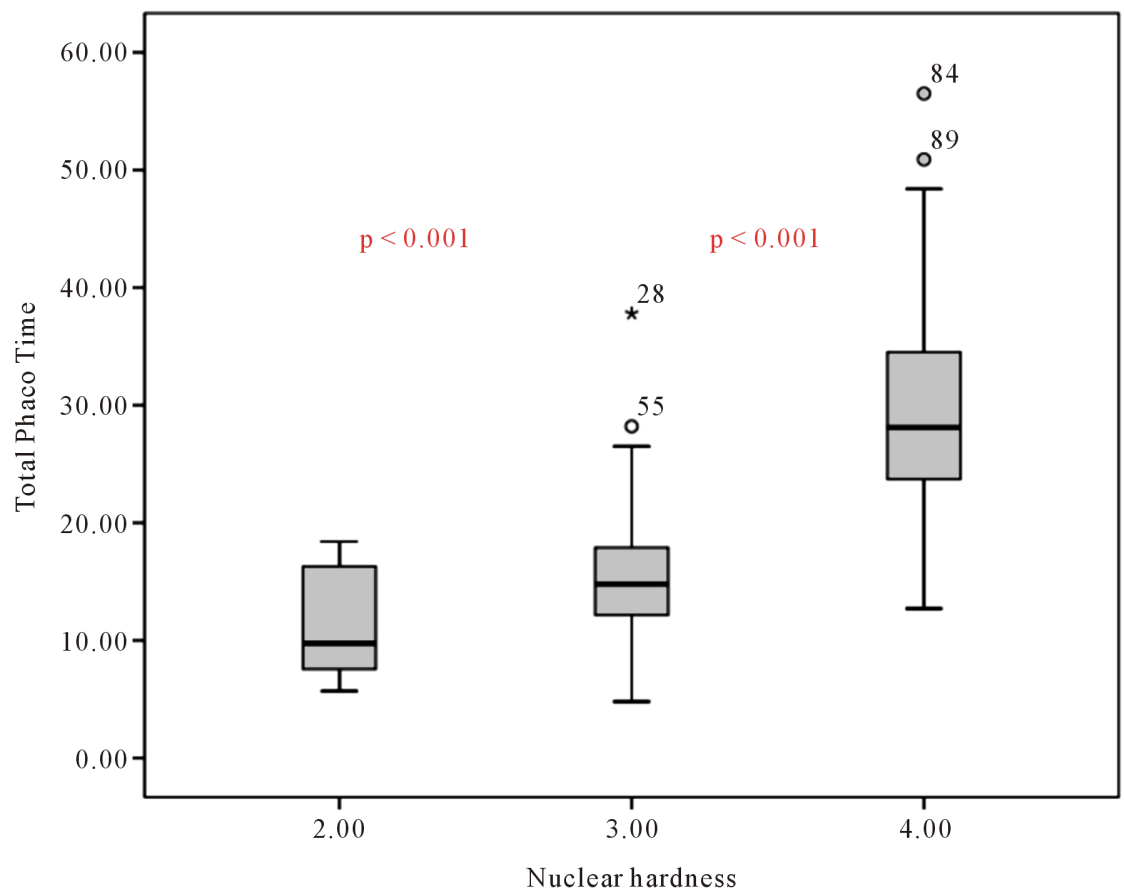

Figure 5. Box plot representing the distribution of the total phaco time (TPT) outcomes using the 21G phaco tip in eyes with cataract of nuclear hardness $2 / 2+, 3 / 3+$ and $4 / 4+$. The boxes represent the interquartile range (difference between the upper $75 \%$ and lower quartile $25 \%$ ); the thick black lines, the median; the whiskers, the highest and lowest values that were not outliers or extreme values; circles, outliers (values that are between 1.5 and 3 times the interquartile range); asterisks, extreme values (values that are more than 3 times the interquartile range). 


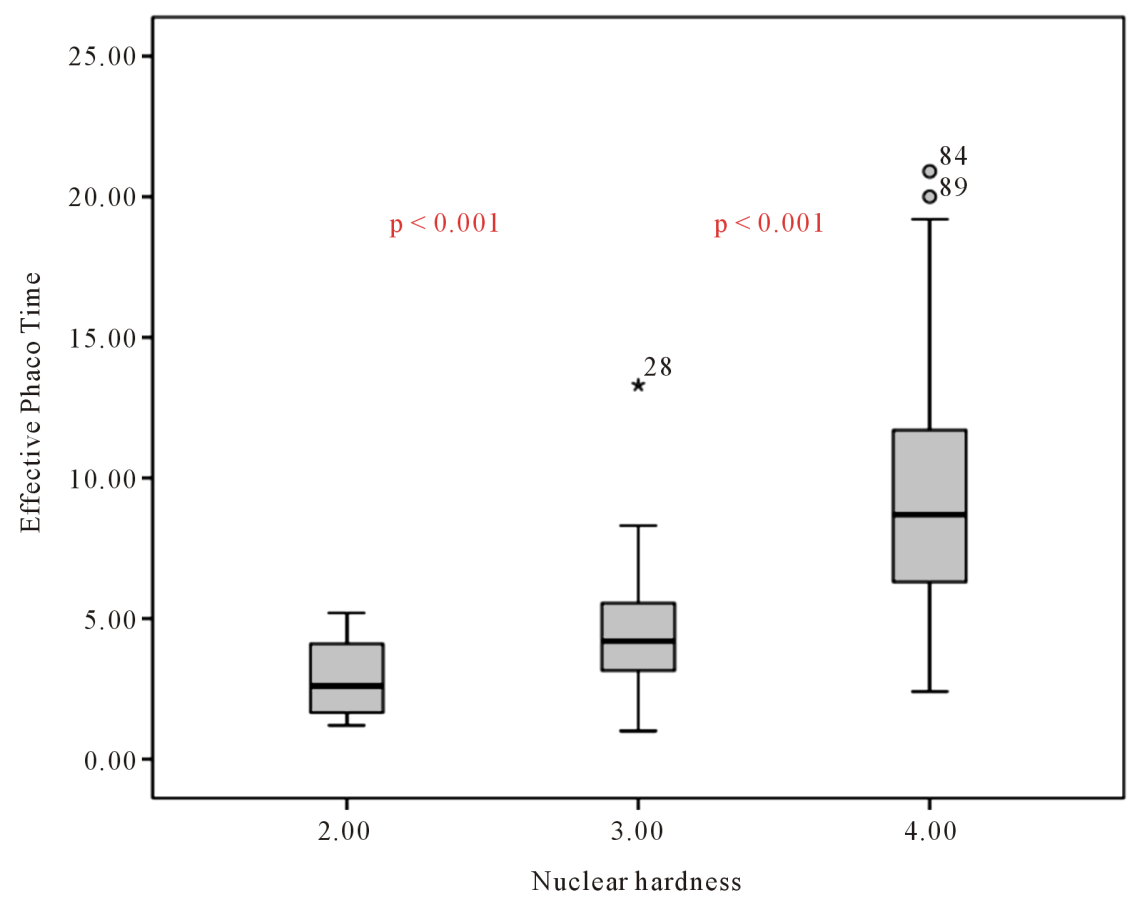

Figure 6. Box plot representing the distribution of the effective phaco time (EPT) outcomes using the 21G phaco tip in eyes with cataract of nuclear hardness $2 / 2+, 3 / 3+$ and $4 / 4+$. The boxes represent the interquartile range (difference between the upper $75 \%$ and lower quartile $25 \%$ ); the thick black lines, the median; the whiskers, the highest and lowest values that were not outliers or extreme values; circles, outliers (values that are between 1.5 and 3 times the interquartile range); asterisks, extreme values (values that are more than 3 times the interquartile range).

reduction, with the subsequent improved anterior chamber stability and physiological protection of the cornea. We compared our results with those of other groups. Although different surgical skills might have an influence on the results, we consider these comparisons as legitimate because we expect comparable experience and skills of surgeons who publish their results in peer reviewed journals. In our sample, reduced TPT and EPT have been obtained which confirms the good performance of the phaco system and ultrasound mode evaluated in terms of surgical time. Specifically, median values of EPT of 3.15 and $5.00 \mathrm{~s}$ were found when using the 20G and 21G phaco tips, respectively. These values are consistently lower than those reported for conventional phacoemulsification cataract surgery with other platforms [12] [13]. Likewise, the EPT values obtained in our series are close tothose reported by other authors combining femtosecond laser cataract surgery platforms with phaco systems [14]-[16]. Reddy and colleagues [15] found a mean EPT of 5.2 seconds in a sample of 56 eyes undergoing cataract surgery using a femtosecond laser. Daya and colleagues [14] found mean EPT values of $9.89 \pm 5.32 \mathrm{~s}$ and $8.58 \pm 4.66 \mathrm{~s}$ after femtosecond laser-assisted and conventional cataract surgery, respectively. In our sample, early postoperative corneal clarity was observed in all cases, which was consistent with the reported phacotimes. It should be considered that shorter absolute phaco time has been shown to be relatedwith less endothelial cell loss [4] [17] [18].

With the two phaco tips used in our series, significant differences in TPT and EPT were found between eyes with cataract of nuclear hardness $3 / 3+$ and $4 / 4+$. Specifically, longer phaco times were required for those cataracts with the harder nuclei, as could be expected. This is consistent with the outcomes reported by other authors showing the relationship between cataract nuclear hardness and phaco time [19]-[21]. Gupta and colleagues [19] found in a longitudinal interventional study with 100 patients undergoing phacoemulsification surgery that the LOCS III grading and Scheimpflug maximum nuclear density had a linear correlation with total ultrasound time $(r=0.627$ and $r=0.802$, respectively). These authors also reported a significant correlation of cataract grade and cumulative dissipated energy (CDE). Therefore, the longer the phaco time, the more energy entered the anterior chamber increasing the risk for damage to the intraocular structures. The achievement of shorter phaco times with the Visalis500 is one factor promoting potentially safer procedures for all types of cataracts. In our series, mean EPT values of 6.70 and $8.70 \mathrm{~s}$ were found in eyes with hard cataracts $(4 / 4+)$ using the $20 \mathrm{G}$ and $21 \mathrm{G}$ phaco 
tips, respectively. These durations are shorter than those reported with other types of phaco systems when used for conventional cataract surgery [19]-[22]. Simanjuntak et al. [22] assessed in 40 eyes from 25 patients with hard mature cataract grades 3 - 4 the efficacy and safety of a modified double extra sharp chopper for removal of hard cataracts and found a mean EPT of $23.73 \pm 5.75$ s. Future studies should confirm the potential benefit of the reduced phaco time with the evaluated system, especially in hard cataracts, by analyzing the changes in corneal endothelial cell density and anatomical aspects of other intraocular structures.

Finally, a significant difference was found in the current study in terms of TPT $(p=0.0011)$ and EPT $(p=$ 0.0032 ) between the $20 \mathrm{G}$ and $21 \mathrm{G}$ phaco tips. Specifically, the use of the tip requiring the smallest corneal incision (21G) was associated to longer total and effective phaco times. This is consistent with previous studies confirming the relationship between phaco tip and phacoemulsification efficiency [22]. In any case, the EPT values achieved with both $20 \mathrm{G}$ and $21 \mathrm{G}$ tips in our series were consistently lower than those reported for conventional phacoemulsification cataract surgery with other platforms [12] [13], as previously mentioned. Schriefl et al. [12] showed that a significant decrease in EPT was achievable with a $21 \mathrm{G}$ phaco tip by switching from low to high fluidic settings. However, high fluidic settings can lead to more iatrogenic effects on ocular tissue [23]. In contrast, the use of smaller corneal incisions in cataract surgery has some beneficial effects, especially in terms of safety [24].

A limitation of this study is that only one phaco system was used and the results were compared with published results of other authors. Ideally a randomized study comparing different phaco systems, used by one surgeon, should be compared, which is, however, a challenge in a routine clinical setting.

\section{Conclusion}

In conclusion, the Visalis 500 phaco platform allows the cataract surgeon to reduce total and effective phaco time significantly, even in hard mature cataracts. More significant postoperative anterior chamber stability, corneal clarity and consequently an almost immediate visual recovery are then expected with this phaco system. With both phaco tips, reduced levels of phaco time are achieved, and EPT is significantly lower with the $20 \mathrm{G}$ tip.

\section{References}

[1] Fishkind, W.J. (2013) The Phaco Machine: Analysing New Technology. Current Opinion in Ophthalmology, 24, 41-46. http://dx.doi.org/10.1097/icu.0b013e32835b0770

[2] Zacharias, J. and Ohl, C.D. (2013) Fluid Dynamics, Cavitation, and Tip-to-Tissue Interaction of Longitudinal and Torsional Ultrasound Modes during Phacoemulsification. Journal of Cataract \& Refractive Surgery, 39, 611-616. http://dx.doi.org/10.1016/j.jcrs.2012.10.050

[3] Mahdy, M.A., Eid, M.Z., Mohammed, M.A., Hafez, A. and Bhatia, J. (2012) Relationship between Endothelial Cell Loss and Microcoaxial Phacoemulsification Parameters in Noncomplicated Cataract Surgery. Journal of Clinical Ophthalmology, 6, 503-510. http://dx.doi.org/10.2147/opth.s29865

[4] Baradaran-Rafii, A., Rahmati-Kamel, M., Eslani, M., Kiavash, V. and Karimian, F. (2009) Effect of Hydrodynamic Parameters on Corneal Endothelial Cell Loss after Phacoemulsification. Journal of Cataract \& Refractive Surgery, 35, 732-737. http://dx.doi.org/10.1016/j.jcrs.2008.12.017

[5] Fishkind, W., Bakewell, B., Donnenfeld, E.D., Rose, A.D., Watkins, L.A. and Olson, R.J. (2006) Comparative Clinical Trial of Ultrasound Phacoemulsification with and without the WhiteStar System. Journal of Cataract \& Refractive Surgery, 32, 45-49. http://dx.doi.org/10.1016/j.jcrs.2005.10.026

[6] Ursell, P.G., Spalton, D.J. and Tilling, K. (1997) Relation between Postoperative Blood-Aqueous Barrier Damage and LOCSIII Cataract Gradings Following Routine Phacoemulsification Surgery. British Journal of Ophthalmology, 81, 544-547. http://dx.doi.org/10.1136/bjo.81.7.544

[7] Patricio, M.S., Almeida, A.C., Rodrigues, M.P., Guedes, M.E. and Ferreira, T.B. (2013) Correlation between Cataract Grading by Scheimpflug Imaging and Phaco Time in Phacoemulsification Using Peristaltic and Venturi Pumps. European Journal of Ophthalmology, 23, 789-792. http://dx.doi.org/10.5301/ejo.5000293

[8] Karaguzel, H., Karalezli, A. and Aslan, B.S. (2009) Comparison of Peristaltic and Venturi Pumps in Bimanual Microincisional Cataract Surgery. International Ophthalmology, 29, 471-475. http://dx.doi.org/10.1007/s10792-008-9267-6

[9] Cahoon, J.M., Gupta, I., Gardiner, G., Shi, D., Zaugg, B., Pettey, J.H., Barlow Jr., W.R. and Olson, R.J. (2015) Comparison of Venturi and Peristaltic Vacuum in Phacoemulsification. Journal of Cataract \& Refractive Surgery, 41, 428432. http://dx.doi.org/10.1016/j.jcrs.2014.12.043 
[10] Chylack, L.T.J., Wolfe, J.K., Singer, D.M., Leske, M.C., Bullimore, M.A., Bailey, I.L., Friend, J., McCarthy, D. and Wu, S.Y. (1993) The Lens Opacities Classification System III. The Longitudinal Study of Cataract Study Group. Archives of Ophthalmology, 111, 831-836. http://dx.doi.org/10.1001/archopht.1993.01090060119035

[11] Augustin, A.J. (2007) Augenheilkunde 3. Springer, Berlin, 1157-1167.

[12] Schriefl, S.M., Stifter, E. and Menapace, R. (2014) Impact of Low versus High Fluidic Settings on the Efficacy and Safety of Phacoemulsification. Acta Ophthalmologica, 92, e454-e457. http://dx.doi.org/10.1111/aos.12200

[13] Wahab, S., Faiz-ur-Rub, K. and Hargun, L.D. (2010) Comparison of Conventional Phacoemulsification Technique vs. Cool Phacoemulsification Technique with the Importance of Phacoemulsification Variables. Journal of the College of Physicians and Surgeons-Pakistan, 20, 449-453.

[14] Daya, S.M., Nanavaty, M.A. and Espinosa-Lagana, M.M. (2014) Translenticular Hydrodissection, Lens Fragmentation, and Influence on Ultrasound Power in Femtosecond Laser-Assisted Cataract Surgery and Refractive Lens Exchange. Journal of Cataract \& Refractive Surgery, 40, 37-43. http://dx.doi.org/10.1016/j.jcrs.2013.07.040

[15] Reddy, K.P., Kandulla, J. and Auffarth, G.U. (2013) Effectiveness and Safety of Femtosecond Laser-Assisted Lens Fragmentation and Anterior Capsulotomy versus the Manual Technique in Cataract Surgery. Journal of Cataract \& Refractive Surgery, 39, 1297-1306. http://dx.doi.org/10.1016/j.jcrs.2013.05.035

[16] Conrad-Hengerer, I., Hengerer, F.H., Schultz, T. and Dick, H.B. (2012) Effect of Femtosecond Laser Fragmentation of the Nucleus with Different Softening Grid Sizes on Effective Phaco Time in Cataract Surgery. Journal of Cataract \& Refractive Surgery, 38, 1888-1894. http://dx.doi.org/10.1016/j.jcrs.2012.07.023

[17] O’Brien, P.D., Fitzpatrick, P., Kilmartin, D.J. and Beatty, S. (2004) Risk Factors for Endothelial Cell Loss after Phacoemulsification Surgery by a Junior Resident. Journal of Cataract \& Refractive Surgery, 30, 839-843. http://dx.doi.org/10.1016/S0886-3350(03)00648-5

[18] Fine, I.H., Packer, M. and Hoffman, R.S. (2004) Power Modulations in New Phacoemulsification Technology: Improved Outcomes. Journal of Cataract \& Refractive Surgery, 30, 1014-1019. http://dx.doi.org/10.1016/j.jcrs.2003.09.062

[19] Gupta, M., Ram, J., Jain, A., Sukhija, J. and Chaudhary, M. (2013) Correlation of Nuclear Density Using the Lens Opacity Classification System III versus Scheimpflug Imaging with Phacoemulsification Parameters. Journal of Cataract \& Refractive Surgery, 39, 1818-1823. http://dx.doi.org/10.1016/j.jcrs.2013.05.052

[20] Belíkova, J. and Synek, S. (2013) Correlation of Age-Related Cataract Density Graded by the Scheimpflug Imaging System with Visual Function and Phacoemulsification Energy. Collegium Antropologicum, 37, 25-30.

[21] Nixon, D.R. (2010) Preoperative Cataract Grading by Scheimpflug Imaging and Effect on Operative Fluidics and Phacoemulsification Energy. Journal of Cataract \& Refractive Surgery, 36, 242-246. http://dx.doi.org/10.1016/j.jcrs.2009.08.032

[22] Farukhi, A.M., Stagg, B.C., Ronquillo Jr., C., Barlow Jr., W.R., Pettey, J.H., Olson, R.J., Gupta, I. and Jensen, J.D. (2014) Effect of Phaco Tip Diameter on Efficiency and Chatter. Journal of Cataract \& Refractive Surgery, 40, 811817. http://dx.doi.org/10.1016/j.jcrs.2013.09.021

[23] Vasavada, A.R., Praveen, M.R., Vasavada, V.A., Vasavada, V.A., Raj, S.M., Asnani, P.K. and Garg, V.S. (2010) Impact of High and Low Aspiration Parameters on Postoperative Outcomes of Phacoemulsification: Randomized Clinical Trial. Journal of Cataract \& Refractive Surgery, 36, 588-593. http://dx.doi.org/10.1016/j.jcrs.2009.11.009

[24] Elkady, B., Piñero, D. and Alió, J.L. (2009) Corneal Incision Quality: Microincision Cataract Surgery versus microcoaxial Phacoemulsification. Journal of Cataract \& Refractive Surgery, 35, 466-474.

http://dx.doi.org/10.1016/j.jcrs.2008.11.047 


\section{Submit or recommend next manuscript to SCIRP and we will provide best service for you:}

Accepting pre-submission inquiries through Email, Facebook, Linkedin, Twitter, etc A wide selection of journals (inclusive of 9 subjects, more than 200 journals)

Providing a 24-hour high-quality service

User-friendly online submission system

Fair and swift peer-review system

Efficient typesetting and proofreading procedure

Display of the result of downloads and visits, as well as the number of cited articles

Maximum dissemination of your research work

Submit your manuscript at: http://papersubmission.scirp.org/ 